\title{
Estimativa do Rendimento em Madeira Serrada de Pinus para Duas Metodologias de Desdobro
}

\author{
Mauro Itamar Murara Junior ${ }^{1}$, Márcio Pereira da Rocha², \\ Paulo Fernando Trugilho ${ }^{3}$
}

\author{
${ }^{1}$ Departamento de Tecnologia da Madeira, Universidade do Contestado - UnC, Canoinhas/SC, Brasil \\ ${ }^{2}$ Departamento de Engenharia e Tecnologia Florestal, Universidade Federal do Paraná - UFPR, Curitiba/PR, Brasil \\ ${ }^{3}$ Departamento de Ciências Florestais, Universidade Federal de Lavras - UFLA, Lavras/MG, Brasil
}

\begin{abstract}
RESUMO
Esta pesquisa objetivou determinar o rendimento em madeira serrada de pinus para duas metodologias de desdobro em classes diamétricas, ajustando-se equações para a estimativa destes rendimentos. Utilizaram-se toras de Pinus taeda, com diâmetros variando entre $18 \mathrm{e}$ $44 \mathrm{~cm}$, separadas em classes diamétricas. As toras foram desdobradas em tábuas de três larguras e uma espessura. Utilizaram-se duas metodologias de desdobro, convencional e programado, com modelos de corte específicos por classe. Os rendimentos variaram de $37,03 \%$ a $46,75 \%$ (desdobro convencional) e de $44,93 \%$ a $63,58 \%$ (desdobro programado). Os coeficientes de determinação $\left(\mathrm{R}^{2}\right)$ foram considerados altos, permitindo se estimarem estatisticamente os rendimentos pela equação ajustada. O rendimento foi influenciado pelo sistema de desdobro utilizado. A classificação das toras e os modelos de corte proporcionaram aumento do rendimento. Os modelos estatísticos obtidos podem ser utilizados para a estimativa do rendimento nos dois sistemas de desdobro utilizados.
\end{abstract}

Palavras-chave: modelos de corte, Pinus, estimativa de volume.

\section{Estimate of Pine Lumber Yield Using Two Sawing Methods}

\begin{abstract}
This study aimed to determine the yield of pine lumber for two sawing methods and different diameter classes with equation adjustment for these estimated yields. We used logs of Pinus taeda in five diameter classes ranging between 18 and $44 \mathrm{~cm}$. The logs were processed in boards with three width and one thickness dimensions. Two sawing methods: conventional and programmed were used for each diameter class. The yields in lumber ranged from $37.03 \%$ to $46.75 \%$ for the conventional sawing method and from $44.93 \%$ to $63.58 \%$ for the programmed sawing method. The coefficients of determination (R2) were considered high, allowing statistical estimate of the yields based on adjusted equation. Lumber yield was directly affected by the sawing methods used. The classification of the logs and the sawing methods contributed to increased yield. The statistical models obtained could be used to estimate lumber yield for the two sawing methods used.
\end{abstract}

Keywords: cutting models, Pinus, estimated volume. 


\section{INTRODUÇÃO}

Ao longo das últimas décadas, o perfil de consumo de madeiras oriundas de reflorestamento mudou substancialmente em função das restrições de exploração e da disponibilidade de espécies florestais nativas. A cadeia produtiva estendeu-se para as essências de rápido crescimento, plantadas e manejadas. A grande concentração de plantios de pinus é na Região Sul do Brasil, especificamente os Estados do Paraná e de Santa Catarina, onde as espécies mais plantadas são Pinus elliottii e Pinus taeda.

A madeira de pinus exerce importante papel na Região Sul no fornecimento de matéria-prima para indústrias de celulose, laminados, painéis compostos e, em alguns polos da Região, como o principal recurso madeireiro das indústrias de móveis. Devido à elevada demanda desta matéria-prima na Região Sul nos últimos anos, houve um grande aumento no preço das toras, incidindo no custo final dos produtos acabados. Desta forma, surgiu a necessidade de se otimizar o processo de desdobro das toras, quando a madeira tem finalidade para a indústria de serrados e moveleira.

Associado à baixa oferta de toras de pinus, o baixo rendimento em madeira serrada obtido pelas serrarias tem dificultado a competição das indústrias de móveis na exportação, pois estas ainda utilizam tecnologias ultrapassadas e maquinários que não proporcionam bons rendimentos. Segundo Ribas (1989), os rendimentos atuais giram em torno de $44 \%$ e a utilização de novas tecnologias de desdobro pode proporcionar significativos incrementos no aproveitamento das toras.

$O$ processo de transformação de uma tora de madeira de seção circular em peças de seções retangulares e quadradas é chamado sistema de desdobro. Existem vários sistemas de desdobro que podem ser adaptados às mais diversas necessidades, variedades de espécies e formas das toras. Segundo Vianna Neto (1984), do ponto de vista geométrico e anatômico, as possibilidades que envolvem praticamente todas as variantes de desempenho de corte de uma tora podem ser agrupadas em três classes: 1) em função dos anéis de crescimento (cortes tangenciais ou radiais); 2) em relação ao eixo longitudinal da tora (corte paralelo ao eixo ou paralelo à casca), e 3) em função da sequência dos cortes (sucessivos, simultâneos e alternados). A sequência dos cortes depende basicamente do tipo de maquinário utilizado e do produto final desejado (Rocha, 2001).

De acordo com Leite (1994), a decisão de um operador, ao desdobrar uma tora, dificilmente resultará num nível ótimo de rendimento em madeira serrada, porque raramente este operador conseguirá obter a melhor visualização de todas as alternativas no pouco tempo que terá para a tomada de decisão. Portanto, a necessidade da seleção de toras por classes diamétricas e o estabelecimento de modelos de corte, os quais são fatores de importância primária, visam a atingir níveis de rendimentos mais elevados para aquele determinado tipo de material que está sendo utilizado. Desta maneira, é possível melhorar o rendimento em madeira serrada para cada classe diamétrica utilizada.

Basicamente, a metodologia de se desdobrarem toras pode ser definida de duas maneiras, desdobro convencional e desdobro programado. Chama-se desdobro convencional a metodologia que utiliza, na maioria das vezes, o sistema de corte tangencial em sanduíche, o qual consiste em 'fatiar' a tora, tentando obter o maior número de peças. Um sistema de desdobro programado constitui-se em utilizar um sistema de corte previamente estudado, objetivando a máxima utilização da tora (Leite, 1994).

Nas serrarias baseadas em projetos convencionais, a escolha da maneira pela qual as toras serão processadas depende da experiência e do bom senso dos operadores. Na prática e, na grande maioria dos casos, a decisão é aleatória. O posicionamento das toras, o número de cortes e o dimensionamento dos blocos e pranchas, visando à obtenção de produtos mais adequados e à eliminação dos defeitos das toras, são alguns dos fatores que afetam diretamente o rendimento do processo de corte, os produtos obtidos e, consequentemente, os custos de produção e nas receitas geradas. Na realidade, é um conjunto de fatores que dificilmente pode ser otimizado sem a existência de ferramentas adequadas (Wipieski et al., 2002 citados por Biasi, 2005). Segundo os autores, atualmente encontram-se disponíveis no mercado sistemas capazes de reconhecer e interpretar 
automaticamente as diferenças existentes entre as toras a serem processadas, assegurando maior racionalidade no posicionamento e nos diferentes cortes a serem efetuados. Tratam-se de sistemas de alta tecnologia, os quais possibilitam a maximização no aproveitamento da matéria-prima. Embora disponíveis, estes sistemas geralmente são caros e, em serrarias de pequeno e médio portes, dificilmente podem ser justificados em uma análise econômica.

Certamente, a metodologia de desdobro aplicada em uma serraria de pinus irá determinar maior ou menor aproveitamento da matéria-prima. Porém, a determinação precisa e rápida dos rendimentos obtidos numa serraria, para as mais variadas classes diamétricas e os variados produtos, é fator importante na composição dos custos de produção.

Quando se seguem metodologias de desdobro distintas, dentro de uma amplitude diamétrica e sem variação dos produtos serrados obtidos, tornase possível a obtenção de equações que permitam a estimativa do rendimento em madeira serrada com elevada precisão.

Desta forma, esta pesquisa objetivou a determinação do rendimento em madeira serrada de pinus para duas metodologias de desdobro e diferentes classes diamétricas, com o ajuste de equações para a estimativa destes rendimentos.

\section{MATERIAL E MÉTODOS}

\subsection{Local do experimento e seleção das toras}

Este estudo foi realizado em uma serraria localizada na cidade de São Bento do Sul-SC, cuja principal produção de madeira serrada é constituída de peças com dimensões nominais de 55, 80 e $110 \mathrm{~mm}$ de largura, e $27 \mathrm{~mm}$ de espessura, destinadas à produção de móveis para exportação.

No desdobro principal, foi utilizada uma serrafita com diâmetro de volantes de 1,25 m e altura de corte de $80 \mathrm{~cm}$. Para resserragem das costaneiras, foi utilizada uma serra-fita horizontal de dois cabeçotes com volantes de 1,25 m de diâmetro e altura de corte de $50 \mathrm{~cm}$. Para o ajuste das larguras das tábuas originadas da resserragem, foram utilizadas duas serras circulares refiladeiras duplas com altura de corte de $80 \mathrm{~mm}$. Os semiblocos obtidos no desdobro principal foram direcionados para uma serra circular múltipla de um eixo, com altura de corte de $110 \mathrm{~mm}$. As costaneiras geradas pelo primeiro corte da tora foram resserradas na serra-fita horizontal com dois cabeçotes e o semibloco central foi encaminhado para a operação de resserragem em serra circular múltipla (Figura 1).

A espécie utilizada para o estudo foi Pinus taeda, cujas toras foram obtidas de florestas próprias da indústria, com aproximadamente 27 anos de idade. As classes diamétricas utilizadas variaram de $18 \mathrm{~cm}$ até $40 \mathrm{~cm}$ de diâmetro. Foram utilizadas 100 toras de pinus, divididas em cinco classes diamétricas, sendo 20 toras para cada classe diamétrica e todas com 3,00 m de comprimento (Tabela 1). As toras tiveram seus diâmetros medidos na ponta grossa (d1) e na ponta fina (d2), dos quais, através de média aritmética, obteve-se um diâmetro médio, que foi utilizado para o cálculo do volume das toras e suas classificações por classe diamétrica. De cada classe diamétrica, foram separadas dez toras para desdobro em duas metodologias diferentes.

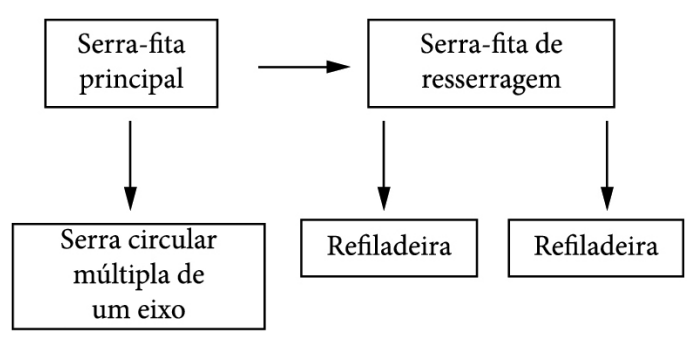

Figura 1. Layout dos equipamentos na serraria utilizada no desdobro das toras.

Figure 1. Layout of equipments at the sawmill used for the log processing.

Tabela 1. Seleção de toras de pinus em cinco classes diamétricas para desdobro e obtenção de índices de rendimento em madeira serrada por classe diamétrica para dois métodos de desdobro.

Table 1. Selection of logs of pinus in five diameter classes for log processing and achieve rates of yield on lumber per diameter class for two sawn methods.

\begin{tabular}{cccc|}
$\begin{array}{c}\text { Classe } \\
\text { diamétrica }\end{array}$ & $\begin{array}{c}\mathbf{N}^{\mathbf{0}} \text { de } \\
\text { toras }\end{array}$ & $\begin{array}{c}\text { Diâmetro } \\
(\mathbf{c m})\end{array}$ & $\begin{array}{c}\text { Comprimento } \\
(\mathbf{m})\end{array}$ \\
\hline 1 & 20 & $18,0-24,0$ & 3,00 \\
\hline 2 & 20 & $24,1-28,0$ & 3,00 \\
\hline 3 & 20 & $28,1-34,0$ & 3,00 \\
\hline 4 & 20 & $34,1-38,0$ & 3,00 \\
\hline 5 & 20 & $38,1-44,0$ & 3,00 \\
\hline Total & 100 & & \\
\hline
\end{tabular}




\subsection{Sistemas de desdobro utilizados}

Foram definidas duas metodologias de desdobro, sendo uma chamada de desdobro convencional e outra chamada de desdobro programado. Para as duas metodologias, as dimensões das peças serradas foram de $27 \mathrm{~mm}$ de espessura e 55, 80, e $110 \mathrm{~mm}$ de largura. Tais dimensões foram definidas em função das necessidades da empresa para a confecção de painéis de madeira.

\subsubsection{Sistema de desdobro convencional}

O sistema de desdobro convencional consistiu de uma metodologia utilizada pela serraria, na qual as toras não eram classificadas antes do desdobro, tornando-se, dessa forma, pouco eficiente e produtivo. Na medida em que não havia um sistema de classificação por classes diamétricas das toras, no momento em que a tora entrava na serraria para desdobro na serra principal, a mesma era classificada visualmente pelo operador da máquina. Neste momento, o operador optava pelo melhor posicionamento da tora sobre o carro porta-tora, definindo o modelo de corte a ser desenvolvido para cada uma, de forma visual.

Todo o lote composto de 50 toras foi processado sem que houvesse classificação das toras e um modelo de corte específico para cada classe diamétrica, com os diâmetros variando entre $18 \mathrm{~cm}$ e $44 \mathrm{~cm}$. O desdobro primário da tora foi determinado de acordo com a acuidade visual do operador, por meio da qual cada tora era analisada primeiramente para que, na sequência, se pudesse dar início ao processo de desdobro.

\subsubsection{Sistema de desdobro programado}

A segunda etapa do estudo, com as outras 50 toras, foi realizada na mesma linha de desdobro para cada classe diamétrica, porém obedecendo a um modelo de corte pré-estabelecido e específico para cada uma delas. Desta forma, as toras foram separadas por classe diamétrica em cinco grupos de dez toras. Em seguida, cada grupo foi desdobrado seguindo o modelo de corte pré-estabelecido (Figura 2). Para a elaboração dos modelos de corte, foi utilizado o programa MaxiTora, da empresa Optimber - Otimização e Informática.

\subsection{Cálculo do volume de madeira serrada}

Para o cálculo do volume em madeira serrada, todas as tábuas obtidas em cada classe diamétrica tiveram suas espessuras, larguras e comprimentos medidos. Foram tomadas duas medidas da espessura, sendo uma em cada topo, com auxílio de paquímetro digital. Da mesma forma, foram tomadas duas medidas da largura, uma em cada topo da tábua,
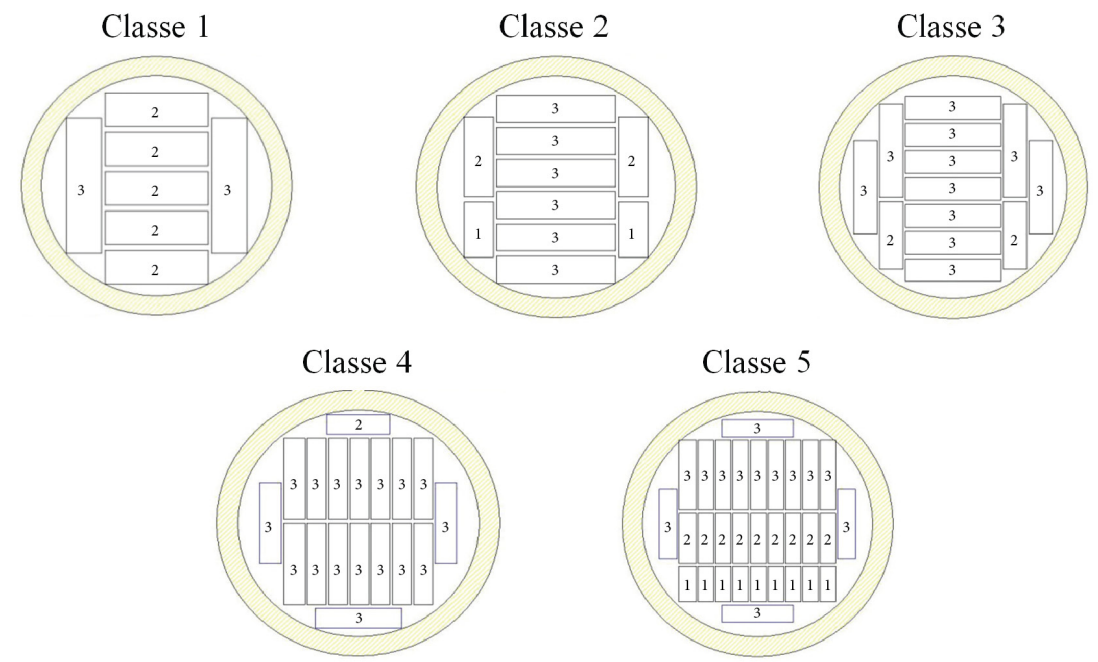

Figura 2. Modelos de corte estabelecidos para desdobro de toras de pinus para cinco classes diamétricas. Classe $1=18,0$ a $24,0 \mathrm{~cm}$; classe $2=24,1$ a $28,0 \mathrm{~cm}$; classe $3=28,1$ a $34,0 \mathrm{~cm}$; classe $4=34,1$ a $38,0 \mathrm{~cm} ;$ classe $5=38,1$ a $44,0 \mathrm{~cm}$.

Figure 2. Cutting models set to processing pinus logs for five diameter classes. Class $1=18.0$ to $24.0 \mathrm{~cm}$; class $2=24.1$ to $28.0 \mathrm{~cm}$; class $3=28.1$ to $34.0 \mathrm{~cm}$; class $4=34.1$ to $38.0 \mathrm{~cm}$; class $5=38.1$ to $44.0 \mathrm{~cm}$. 
com auxílio de trena. Desta forma, foram obtidos 'E' (espessura média da tábua) e 'L' (largura média da tábua). O volume de cada tábua foi determinado através da Equação 1:

$V t=E \times L \times C$

em que: $V t=$ Volume da tábua $\left(\mathrm{m}^{3}\right) ; E=$ Espessura média da tábua $(\mathrm{m}) ; L=$ Largura média da tábua (m); $C=$ Comprimento da tábua $(3,00 \mathrm{~m})$.

Após a determinação do volume em madeira serrada de cada tora nas respectivas classes diamétricas, os mesmos foram somados, obtendose o volume em madeira serrada para cada classe diamétrica para as duas metodologias de desdobro.

\subsection{Cálculo do rendimento em madeira serrada}

Após os processos de desdobro e a determinação do volume serrado para cada classe diamétrica nas duas metodologias de desdobro, foi determinado o rendimento em madeira serrada de cada lote, através da Equação 2:

$$
R \%=\frac{\sum V}{\sum V t} \times 100
$$

em que: $R \%=$ Rendimento em madeira serrada para cada lote (\%); $\Sigma \mathrm{V}=$ Somatória dos volumes de todas as toras do lote $\left(\mathrm{m}^{3}\right) ; \Sigma \mathrm{Vt}=$ Somatória dos volumes de todas as tábuas do lote $\left(\mathrm{m}^{3}\right)$.

\subsection{Análise estatística}

O delineamento experimental utilizado foi $\mathrm{o}$ inteiramente casualisado disposto em esquema fatorial, sendo os fatores a classificação, com dois níveis, para as classes diamétricas, com cinco níveis (cinco classes), com dez repetições.

O efeito da classificação das toras foi considerado como qualitativo e a classe diamétrica, como quantitativa.

\section{RESULTADOS E DISCUSSÃO}

\subsection{Rendimento em madeira serrada}

A Tabela 2 apresenta o resumo da análise de variância para o delineamento experimental utilizado. Verifica-se que os efeitos de classificação, classe diamétrica e interação foram significativos a $1 \%$ de probabilidade. Interação significativa indica que existe dependência entre os fatores e, assim, deve-se fazer o seu desdobramento e avaliar o efeito de classificação dentro de classe diamétrica e viceversa.

A Tabela 3 apresenta os resultados da avaliação do desdobramento da interação e da avaliação do efeito de classificação dentro de classe diamétrica para o rendimento em madeira serrada de pinus, e o teste de comparação múltipla realizado. Observase que os dois sistemas de desdobro diferiram entre si, sendo que o desdobro programado apresentou um rendimento médio superior ao sistema de desdobro convencional. Ao se compararem os dois sistemas em relação às classes diamétricas, verificase que houve um incremento no rendimento para todas estas, sendo que, somente na classe 2, não houve diferença significativa para os dois sistemas

Tabela 2. Resumo da análise de variância do delineamento experimental utilizado.

Table 2. Summary of variance analysis of the experimental chart.

\begin{tabular}{lcc}
\multicolumn{1}{c}{ FV } & GL & QM \\
Classificação (C) & 1 & $2150,1769^{* *}$ \\
Classe Diamétrica (D) & 4 & $582,0328^{\star *}$ \\
C×D & 4 & $132,1936^{* *}$ \\
Resíduo & 90 & 23,6869 \\
Total & 99 & \\
\hline
\end{tabular}

$\mathrm{FV}$ = fonte de variação; $\mathrm{GL}=$ graus de liberdade; $\mathrm{QM}=$ quadrado médio; ${ }^{* *}$ significativo a $1 \%$ de probabilidade.

Tabela 3. Rendimento em madeira serrada de pinus para o sistema de desdobro convencional e o sistema de desdobro programado

Table 3. Yield in lumber of pinus by conventional and programmed cutting system.

\begin{tabular}{|cccc}
\hline Classe & \multicolumn{2}{c}{ Rendimento (\%) } & \multirow{2}{*}{ C.V. } \\
\cline { 2 - 3 } & $\begin{array}{c}\text { Desdobro } \\
\text { convencional }\end{array}$ & $\begin{array}{c}\text { Desdobro } \\
\text { programado }\end{array}$ & $(\%)$ \\
\hline 1 & $37,03 \mathrm{a}$ & $44,93 \mathrm{~b}$ & 17,58 \\
\hline 2 & $45,35 \mathrm{a}$ & $48,02 \mathrm{a}$ & 5,56 \\
\hline 3 & $45,31 \mathrm{a}$ & $53,24 \mathrm{~b}$ & 14,90 \\
\hline 5 & $46,75 \mathrm{a}$ & $58,21 \mathrm{~b}$ & 19,69 \\
\hline 5 & $46,62 \mathrm{a}$ & $63,58 \mathrm{~b}$ & 26,67 \\
\hline Média & 44,21 & 53,60 & \\
\hline
\end{tabular}

C.V. = Coeficiente de variação. Médias seguidas de mesma letra, em cada linha, não diferem estatisticamente pelo teste de Tukey em nível de $5 \%$ de probabilidade. 
utilizados. Tal resultado já era esperado em função de que a classificação das toras e a determinação de um modelo de corte para cada classe diamétrica são fatores determinantes para um melhor resultado no rendimento em madeira serrada.

Manhiça (2010) desdobrou toras de pinus em quatro classes diamétricas, variando entre 24 e $33 \mathrm{~cm}$ de diâmetro, e utilizando dois sistemas de desdobro (aleatório e programado), equivalentes aos utilizados neste estudo. $\mathrm{O}$ autor também observou um aumento no rendimento do desdobro programado em relação ao aleatório. Apesar de trabalhar com amplitudes diamétricas maiores, o autor observou um rendimento médio em madeira serrada de 49,01\% para o desdobro aleatório e $52,14 \%$ para o desdobro programado, os quais foram estatisticamente diferentes e com valores próximos aos encontrados neste estudo.

Comparando-se os resultados dos dois sistemas, observa-se que, com exceção da classe 2 , a diferença entre os dois sistemas foi elevada, atingindo seu valor máximo na classe 5, na qual o desdobro programado teve um rendimento de quase 17 pontos percentuais acima do desdobro convencional. Por outro lado, Manhiça (2010) observou uma variação menor entre os dois sistemas, sendo a maior delas de quase cinco pontos percentuais, observada na classe de menor diâmetro. Esta menor variação pode ser explicada pela menor amplitude diamétrica entre e dentro das classes utilizadas pelo autor.

O desdobramento da interação e a avaliação do efeito da classe diamétrica dentro da classificação para o rendimento em madeira serrada de pinus encontram-se na Tabela 4. Obtiveram-se duas equações de rendimento, sendo uma específica para o desdobro convencional e outra para o desdobro programado.

Tabela 4. Equações de rendimento para madeira desdobrada pelos sistemas convencional e programado. Table 4. Equations of yield for lumber processed by conventional and programmed systems.

Rend $1=31,46031+0,411349 * \mathrm{X}$

Rend $2=24,15299+0,94979 * X$

${ }^{*} \mathrm{X}=$ diâmetro médio da tora; Rend $1=$ toras sem programação; Rend 2 = toras utilizando programação de corte.
Os coeficientes de determinação $\left(\mathrm{R}^{2}\right)$ encontrados para ajuste das equações de estimativa de rendimento em madeira serrada variaram em $63,85 \%$ para as toras desdobradas convencionalmente e em $99,23 \%$ para as toras desdobradas pelo método programado, sendo ambos considerados altos. Isto indica que os valores de rendimento médios para centros de classes utilizadas no experimento podem ser estimados estatisticamente pelas variáveis utilizadas na equação ajustada. Cardoso Júnior (2008), também trabalhando com desdobro programado de pinus em duas linhas de desdobro, encontrou coeficientes de determinação de 95,35\% (linha 1), 94,37\% (linha 2) e 96,64\% comum para as duas linhas, indicando que a estimativa dos volumes é adequada para o sistema de desdobro programado, de acordo com os resultados obtidos neste estudo.

Os modelos estatísticos gerados através da análise da regressão dos rendimentos médios de madeira serrada podem estimar com precisão o rendimento médio que a tora irá proporcionar, de acordo com o sistema de desdobro optado pela serraria. Desta forma, pode ser utilizado como ferramenta para decisão gerencial de compra da matéria-prima, sendo que, a partir do momento em que se obtiver o diâmetro médio da tora, é possível estimar com precisão o respectivo rendimento médio.

A Figura 3 apresenta os resultados obtidos entre o modelo estatístico ajustado e o resultado obtido na serraria para o sistema de desdobro das toras sem a programação de corte. Pode-se observar que, mesmo para as classes 1 e 2 , nas quais as linhas se afastaram, as diferenças entre os rendimentos obtidos e calculados foram pequenas. $\mathrm{Na}$ classe 1, o rendimento obtido foi de $37,03 \%$ (Tabela 3) e o estimado foi de $40 \%$. Na classe 2, o rendimento obtido foi de $45,35 \%$ (Tabela 3 ) e o estimado de $43 \%$. Para as classes 3,4 e 5 , os resultados foram muito similares entre o rendimento obtido e o calculado.

A Figura 4 apresenta os resultados obtidos entre o modelo estatístico ajustado para sistema de desdobro de toras utilizando programação de corte e os números obtidos na realização do experimento. Neste sistema de desdobro, o ajuste foi melhor, no qual se observam valores quase que coincidentes entre os rendimentos obtidos e estimados. 


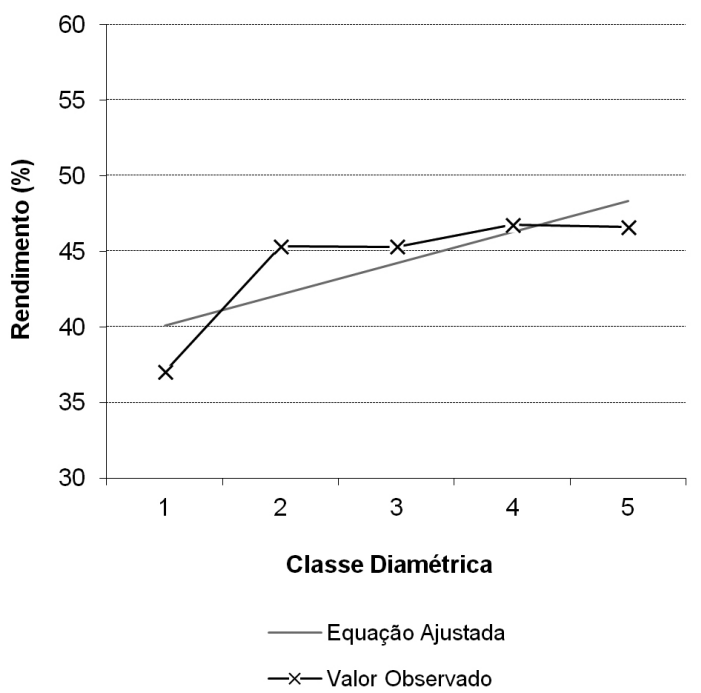

Figura 3. Ajuste do modelo para estimativa de rendimento em madeira serrada para toras de pinus desdobradas sem programação.

Figure 3. Adjust of model to estimate lumber yield for logs of pinus processed without programming system.

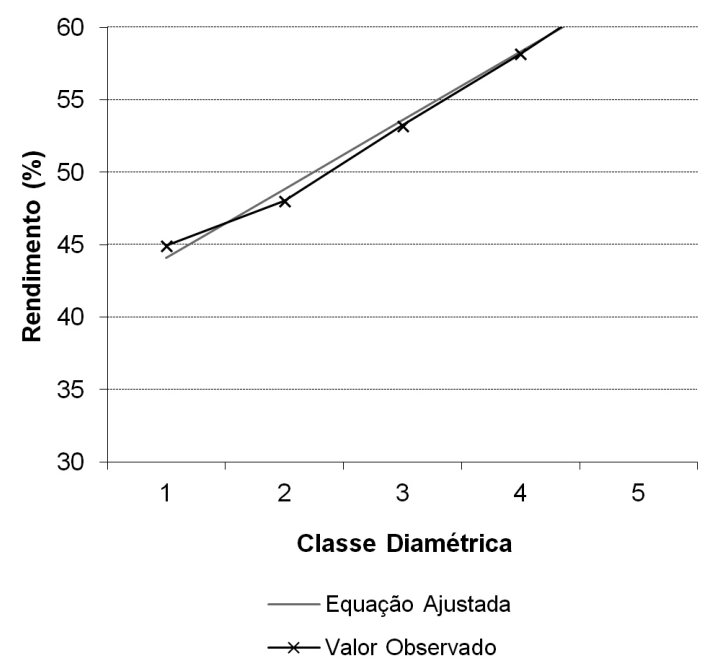

Figura 4. Ajuste do modelo para estimativa de rendimento em madeira serrada para toras de pinus desdobradas com programação.

Figure 4. Adjust of model to estimate lumber yield for logs of pinus processed with programming system.

O erro padrão da estimativa em percentual foi Syx $\%=11,031 \%$, para o sistema de desdobro sem a utilização de programação de corte; já para o sistema programado, o erro percentual obtido foi Syx $\%=9,099 \%$. Desta forma, pode-se observar, nas Figuras 3 e 4, que a estimativa para o desdobro programado foi mais precisa do que para o desdobro convencional. Porém, as duas estimativas mostraram-se com boa precisão.

\section{CONCLUSÕES}

- O rendimento médio em madeira serrada foi diretamente afetado pelo sistema de desdobro utilizado;

- Ao utilizar-se o sistema de desdobro programado, todas as classes diamétricas apresentaram um aumento no rendimento médio em madeira serrada;

- A classe $5(38,1$ a $44 \mathrm{~cm})$ apresentou o maior incremento no rendimento médio em madeira serrada entre o sistema de desdobro convencional e o sistema de desdobro programado;

- A classificação das toras e o estabelecimento de modelos de corte para cada classe diamétrica foi uma forma eficiente de se aumentar o rendimento em madeira serrada de pinus;

- Os dois modelos estatísticos obtidos para a estimativa do volume em madeira serrada de pinus apresentaram boa precisão;

- Entre os dois modelos estatísticos obtidos, o modelo para o desdobro programado foi mais preciso; e

- Os modelos estatísticos obtidos podem ser utilizados para se estimar o rendimento em madeira serrada de pinus utilizando-se toras de 18 a $44 \mathrm{~cm}$ de diâmetro, para os dois sistemas de desdobro utilizados.

\section{STATUS DA SUBMISSÃO}

Recebido: 20/07/2012

Aceito: 07/10/2013

Publicado: 31/12/2013

\section{AUTOR(ES) PARA CORRESPONDÊNCIA}

\section{Mauro Itamar Murara Junior}

Departamento de Tecnologia da Madeira,

Universidade do Contestado - UnC, CEP 89460-000, Canoinhas, SC, Brasil e-mail:mmurara@gmail.com 


\section{REFERENNCIAS}

Biasi CP. Rendimento e eficiência no desdobro de três espécies tropicais [dissertação]. Curitiba: Universidade Federal do Paraná; 2005.

Cardoso Junior AA. Inovação tecnológica na obtenção de madeira serrada de pinus com uso de programa otimizador de desdobro [Tese]. Curitiba: Universidade Federal do Paraná; 2008.

Leite HG. Conversão de troncos em multiprodutos da madeira, utilizando programação dinâmica [tese]. Viçosa: Universidade Federal de Viçosa; 1994.

Manhiça AA. Rendimento e Eficiência no Desdobro de Pinus sp. utilizando modelos de corte numa serraria de pequeno porte [dissertação]. Curitiba: Universidade Federal do Paraná; 2010.

Ribas C, Assini JL, Yamazoe G, Gurgel Garrido LMA. Estudo da influência do diâmetro e do comprimento das toras de Pinus elliottii na produção de madeira serrada e de resíduos de serraria. Revista do Instituto Florestal 1989; 1(1): 51-65.

Rocha MP. Técnicas e planejamento em serrarias. 5. tiragem ed. Fupef; 2001. 105 p. Série didática.

Vianna Neto JA. considerações básicas sobre desdobro de Pinus spp. In: Anais do Seminário sobre processamento e utilização de madeiras de reflorestamento; 1984; Curitiba. Revista Silvicultura 1984; 9(34): 15-19. 